\title{
Family-focused Counseling: A New Dimension in Probation
}

\section{David F. Fike}

Executive Director, Licking County Family Service Association, Newark, Ohio Family Counselor, Lucas County Domestic Relations Court, Toledo, Ohio, 1959-66; Family Caseworker, Licking County Family Service Association, 1966-67

A.B. (Sociology), 1959, Manchester College; M.S.W., 1964, University of Michigan

Probation and child welfare workers are looking for ways to serve their clients more effectively and efficiently. New research on family diagnosis and treatment, role theory, and crisis theory can be helpful. However, not much of this new material has appeared in the literature that is most widely read by probation and child welfare workers. This article describes the theories of family interaction, social role, and crisis; and then, through the use of illustrations from probation and child welfare cases, applies these theories to the primary tasks of workers in these settings-diagnosis, prediction, choice of treatment method, and treatment itself. It also examines the question that is especially applicable to workers carrying unmanageable caseloads: Whom shall you serve, and when?

$\mathbf{R}$ ECENT LITERATURE in psychiatry, psychology, and social work abounds with material related to family diagnosis and treatment, family interaction, role theory as it applies to family dynamics, and crisis theory as it applies to family therapy. However, most. of it lacks any specific application to probation and child welfare work. In these settings, as well as the various voluntary settings, workers are striving to improve the efficiency and effectiveness of their efforts with clients. This paper will explore some of the developing family and related theories which are applicable to probation and child welfare and can aid workers in these settings.
The current trend in the helping professions-psychiatry, psychology, and social work-is toward treating man as he is, a social being who is strongly affected by group associations and who, in turn, affects others. Even psychiatrists, who have long held the one-to-one relationship as almost sacred, are admitting that their work can be destroyed in a moment by the emotional conflict resulting from malfunctioning family relationships. ${ }^{1}$ Therefore, in probation and child welfare work, is it wise to claim that spending an hour a week or an hour a month with the client will do much

1 Nathan W. Ackerman, M.D., The Psychodynamics of Family Life (New York: Basic Books, 1958), p. 10. 
to change him when the remainder of his time is spent in relationships with rejecting parents and siblings or with antisocial friends? Would workers in these settings not be using their limited time more effectively if they were to spend an hour a week or an hour a month with parents working on their relationship with the child, or with the youngster and a group of agemates or siblings? These are questions the worker should be asking himself if he accepts the philosophy of familyfocused counseling. The essential task is to ascertain the family dynamicswhat is going on and what, in the past, has gone on-seen at the point of the worker's entry into the family picture.

\section{Essential Factors}

Among the early authors of this kind of approach to the helping process were Weiss and Monroe. ${ }^{2}$ They imply that to derive a satisfactory understanding of the family one must consider each of four essential factors: (1) the personality characteristics of each family member, (2) the kind of interaction that exists among family members, (3) environmental circumstances, and (4) history (how these other factors have changed or remained stable through time). These are the essential elements if the worker's goal is to restore a family's ability to control a delinquent child or restore a child's ability to accept the control of interested parents or restore a family's ability to care for a dependent child.

2 Viola W. Weiss and Russell R. Monroe, M.D., "A Framework for Understanding Family Dynamics, Parts I and II," Social Casework, January and February 1959, pp. 3-9, 80-87.
This is not new or startling. Probation and child welfare workers helped to develop the concept that environmental, personality, and relationship factors interact to cause the development of antisocial attitudes. This is not a reversal of, but a refinement of, what such workers have been doing for years; but it can also suggest a new approach to counseling on the basis of the family histories that workers have been gathering and writing for years.

A family-focused study would begin in a traditional manner, with compilation of such facts as names and ages of family members; significant datesbirth, marriage, divorce, etc.; and socio-economic factors-race, religion, employment, education, and housing. There would be interest in family contact with other agencies to deter. mine the history of their dealing with the problem now faced jointly. All aspects of family functioning are pertinent: housekeeping, money handling, discipline, and family routine. A description of each family member is important, both as an individual and as he relates to the central problem. An assessment of how these factors have changed, shifted, or remained stable through the family's history is significant.

When we begin to focus on family and interaction, much more must be observed. It is important to assess how, if at all, the family members are affected by their environment. If they are tied to an impoverished neighborhood by low income or large family, are they or are they not accepting of their residence? What is the pattern of dominance in the family? Is it democratically or autocratically oriented? Do all family members gener- 
ally accept the existing dominance pattern? There must be an assessment of family goals and an evaluation of what the members are striving for. Are these goals held in common by all family members? Are they appropriate or obtainable by that family in its circumstances? Special attention should be given to the degree and kinds of satisfaction the family provides for its members, materially and emotionally.

Meier suggests that an individual's family and environment should help him find satisfaction in at least the following "essential striving sentiments": physical security, sexual satisfaction, the expression of hostility, the expression of love, the securing of love, the expression of creativity, the securing of recognition, orientation in terms of place of self and others in society, the securing of membership in a definite human group, and a sense of belonging to a moral order (being right in what one does) . ${ }^{3}$

The final group of elements leading to a family-focused diagnosis relates to social role, a concept that has become commonplace and popular but widely misunderstood. Linton, in his classical definition of social roles, says: "A role represents the dynamic aspect of a status. . . When he puts the rights and duties which constitute the status into effect, he is performing a role. ... Every individual has a series of roles deriving from the various patterns in which he participates. ..."4

3 Elizabeth G. Meier, "Interactions between the Person and His Operational Situations: A Basis for Classification in Casework," Social Casework, November 1965, Pp. 542-49.

4 Ralph Linton, "Status and Role," Social Perspectives on Behavior, Herman D. Stein and Richard A. Cloward, eds. (Glencoc, III.: Free Press, 1958), p. 175.
The man of the household usually occupies the status of husband, father, and employee, and certain role performance is called for from him by his occupation of each of these statuses. Likewise, a teen-age boy is a student, buddy (to other boys), boy friend (to one or more girls), son, and brother. Performance of these roles need not but can lead to problems. The primary role problem is referred to as role conflict. The goal in relation to role is referred to as complementarity. As a simple example, consider the man who for years has worked and supported his family while his wife has accepted with pleasure the responsibility of raising the young children. Then, at some point in time, she goes to work evenings while he is home to care for the children. This adds the status of housekeeper to his group of role performances and adds "breadwinner" to his wife's. This change in a role pattern often leads to role conflict.

To understand family dynamics one must discover which roles are accepted and which are rejected by family members. It is important to discover in what respects there is role conflict. It is important to discover whether members are denied the right to roles they want to perform, by other members or by environmental circumstances. If, in the past, there has been conflict over role performance, it is important to determine what efforts were made to resolve it and whether these efforts were successful.

\section{Appropriate Counseling Approach}

To discover the most appropriate approach to counseling or other forms of assistance, it is important to begin with the family and individual 
goals that will have been elucidated in the study process. To work toward something in which the family is not interested is always a mistake. From the beginning, it is essential to estimate the degree of family adjustment that can be expected from the counseling effort. Is modification of the behavior of an individual member desirable, or is it appropriate to work toward improvement of the interaction between two or more of the members? What effect will such modification have on other family members? Finally, once goals have been determined, it is appropriate to decide on techniques. The best approach for the probation or child welfare worker may be to work with the child, with the child and the parent, or with the parents alone. It may be best to place the child in a group counseling program. It may also be more effective for the worker to counsel the child while another agency works with the parents, and to coordinate this work.

Information from the "familyfocused outline" can give the worker answers to many of the questions he struggles with from day to day. One is the question of prognosis.

\section{Family CRISES}

The advent of delinquency in a child, the finding of dependency of a family's children, an acute need for welfare assistance-any of these occurrences can be viewed as a family crisis. These events create great stress in the family; they are painful and upsetting. Although the causes may have existed for some time, the entrance into the picture of the court, the child welfare worker, or the welfare agency creates for the family a different and unusual crisis situation.
Writing on this subject, Hurwitz, Kaplan, and Kaiser say: "When an acute, stress-producing situation, or a crisis, occurs in a family ... the manner in which the family members respond to the situation and cope with it is a matter of considerable theoretical and practical importance."' These writers studied the question of parental response to the crisis of delinquency of a child. Their effort was to specify some of the things that parents of delinquents must accomplish if recidivism is to be prevented. Their findings are useful. The project staff assumed that parental response to the delinquent act could tell them a great deal about current parent-child relations and thus about the hopefulness or hopelessness of the situation. A pilot study suggested there are only a lim. ited number of ways that parents generally respond to the crisis of delinquency. From study results, the writers concluded that families can generally cope with the crisis situation and prevent future delinquency (1) if they see the child's need for help, (2) if they can see themselves as at least partly responsible, (3) if they can formulate and carry out a constructive, family-oriented plan, (4) if they can communicate effectively with the child and each other, and (5) if they can use the court constructively. They concluded that families probably cannot cope with the crisis situation and that future delinquency is probable (1) if they deny the delinquent act even after official verification, (2) if they project the responsibility for the delinquent act onto the child,

5 Jacob J. Hurwitz, David M. Kaplan, and Elizabeth Kaiser, "Designing an Instrument to Assess Parental Coping Mechanisms," Social Casework, December 1962, p. 527. 
onto bad environmental influences, or onto the other parent, or (3) if they view the court appearance as an unwarranted intrusion into their lives.

This is vital information to have, for effective counseling and for efficient use of time. If the worker finds himself working with a family able to cope and manage pretty much on its own, perhaps monthly contacts with the family to offer guidelines and check on progress is the best plan. If a family is able to cope, perhaps after he has started them toward intrafa. milial resolution of problems, they can contact the worker when his assistance is needed. On the other hand, if the family cannot share responsibility for the child's delinquency or cannot communicate, the worker's first responsibility may be to help them to develop these abilities. Perhaps, in family interviews, parents and child can begin to talk together; perhaps, with the worker there as protector, parents or child or both can say things formerly left unsaid. If, however, this does not develop, his task may be to search for alternatives. Perhaps more appropriate for the child would be individual counseling, or group counseling, or perhaps placement. Perhaps no contact at all is indicated. Then the worker can spend more of his limited time where there is some hope of success.

\section{Theory of Crisis}

The concepts of crisis and coping with crisis situations have been introduced in relation to prognosis in probation and child welfare work. However, the theory of crisis, when attached to a system of family.focused counseling, has much broader application to probation and child welfare practice. A family crisis need not be catastrophic; it need not be a dilemma that demands or even suggests the breakup of the family. A family crisis is simply a situation for which a solution is not easily found and for which normal family problem-solving methods do not suffice. Rapoport says: "Crisis in its simplest terms is defined as 'an upset in a steady state.' . . . In a state of crisis . . . the habitual problem-solving activities are not adequate and do not lead rapidly to the previously achieved balanced state."B Let us take the Jones family. For years Mr. Jones had neglected and rejected the eldest son, resenting him because he was conceived before the marriage and so had "forced" the marriage. Discipline had been severe from an early age. Then on a hot night when the father "had had all he could take from that damned kid," he smacked him and the child's head hit the corner of the table. A trip to the emergency room of the local hospital was required to close the wound, and the matter was referred to the local child welfare agency. With the hostile father-son relationship now in the open, Mrs. Jones had someone-the child welfare worker - to whom she could express all the resentment toward her husband that she had built up through the years for his rejection of Johnny. This situation is not a major departure from the Jones's family routine. Mr. Jones may not have been any more angry than he had been many times before. However, there were new features-the

6 Lydia Rapoport, "The State of Crisis: Some Theoretical Considerations," in Crisis Intervention: Selected Readings, Howard J. Parad, ed. (New York: Family Service Association of America, 1965), p. 24. 
hospital treatment and the referralso now it is not something that can be hidden and now it is not something to which the family members can find a quick solution. This makes it, by definition, a family crisis.

Crisis theorists go on from the point of defining crisis and describe many features of crises that can have great meaning to workers in probation and child welfare settings. ${ }^{7}$ First, the crisis is self-limiting in relation to time; the range is estimated at one to six weeks. In the example above, if the child welfare worker were not to intervene effectively within that period, the family members would perhaps "forget the whole thing" and return to their old routine; or, if Mrs. Jones felt strongly enough about it, she might "settle it" by divorce or separation. Second, a family in a state of crisis normally passes through three stages, attempting to return to a state of equilibrium or harmony. In Stage One, the family members will try to apply old solutions to the new problem.

Mr. Jones would probably attempt to deny to this wife and to the child welfare worker that there was a problem and would attempt to put the blame on Johnny's misbehavior. If Mrs. Jones and the worker were to stand firm these old devices would not work now and the family would be able to move and search for new solutions, which is Stage Two, the problem-solving stage. In this case, it would be appropriate to explore the alternatives of shifting the disciplinary responsibility from $\mathrm{Mr}$. to Mrs. Jones; or shift to the use of isolation in the child's bedroom as an alternative to corporal punishment; or if he is confronted with his rejection of Johnny by a significant person-the child welfare worker-Mr. Jones might voluntarily soften his feelings toward his son. Stage Three is re-equilibrium-a new steady state. If the family and the worker have done their jobs well, this new equilibrium will be on a higher level and severe, unresolvable problems are less likely to arise. However, if they have done their work poorly, the steady state will be at a lower level because an opportunity for improvement will have passed.

The final feature of families in crisis is, perhaps, the most important. When the family is in a state of crisis, the members are more susceptible to, and more accepting of, assistance from a helping person than at any other time. They are without adequate resources to solve their problem. As a matter of fact, the helping person may not even have to do much. "A little help rationally directed and purposefully focused at a strategic time is more effective than more extensive help given at a period of less emotional accessibility."8 These are times when individuals and families can make very significant changes if the worker gives the right help, or if he encourages the family members to look at themselves in a different way at this time.

\section{Family Dynamics}

The following case material illustrates the usefulness of the foregoing concepts to a worker. This case is presented more to describe process 
than content, and more to describe movement than causation of movement.

The Barlow family had five members. The father, Harold, a 37-yearold skilled factory worker with substantial income, and the mother, Sally, a 34-year-old housewife, had been married almost nineteen years. The children, Hal (161/2), Jean (13), and Barbara $\left(11 \frac{1}{2}\right)$, were attractive and healthy. The daughters achieved average grades in school, but Hal had failed all his high-school courses the previous year and was repeating them when contact was initiated. The family lived in an almost new, ranch-style home in a middle-class neighborhood. Mrs. Barlow and the daughters were active in a conservative, Protestant church, but Mr. Barlow and $\mathrm{Hal}$ were not.

Hal was referred to the juvenile court by his father in September 1965 as a runaway. The worker's contact with the family began at that point. The set of circumstances that culminated in the court referral had begun the previous spring. Hal was failing in school and, in addition, had been suspended for habitual, minor infractions of school rules. Family and school efforts to cope with the situation had been fruitless until, on Mr. Barlow's initiative and against $\mathrm{Hal}$ 's will, the boy was placed in a military school. Hal remained there for some five months, then went AWOL and returned home. When he received a cold, probably hostile, reception at home, he ran away again, whereupon his father authorized his arrest. A juvenile court hearing followed.

The hearing itself and early family contacts with the probation worker revealed a wide difference of opinion between the parents about the cause of Hal's delinquency and the solution to it. Mr. Barlow felt Hal was basically defiant and mean and he wanted the court to "lock him up for a while" to "break" him of these traits. Mrs. Barlow, on the other hand, felt that she, her husband, and Hal had created this set of circumstances and that they must work together to resolve it. She welcomed the worker's help in this effort.

The worker's next effort was to talk with $\mathrm{Mr}$. Barlow, and with $\mathrm{Hal}$ and Mr. Barlow together, to determine to what extent the father could be encouraged to establish a more positive relationship with his son. The theme that Mr. Barlow chose in his interview was one of how much he had done for his son and how poorly he had been repaid. The military school cost him $\$ 2,400$ per year; he worked long, hard hours to support his family; and he had moved them into a nice, new home. Hal would not even finish high school so he could make something of himself. Finally, after nearly an hour of such complaints, he stopped and tears came to his eyes as he said, "He hates me and I can hardly stand it." This revelation provided a family goal and the worker pressed this issue just enough to make the point. Perhaps there were things that could be done to diminish the hostility of this father-son relationship.

In the next several weeks a number of things happened. Mr. Barlow purchased a wrecked, salvageable car and for weeks he and his son worked on it each evening, side by side, repairing it for Hal's use. One night Mr. Barlow 
took his son to the plant, where they spent an eight-hour shift togetherMr. Barlow at work and $\mathrm{Hal}$ observing, first-hand, how the family income was earned.

The relationship was becoming, it seemed, wonderfully constructive. Hal was achieving and behaving better at school than he had for several years. Then, in spring 1966 another crisis occurred. The marital relationship that for years, beneath the surface, had been hostile suddenly exploded. There were fights, constant tension, and Mrs. Barlow insisted on a divorce. What happened was this: In earlier periods, when $\mathrm{Hal}$ and his father were at odds, Hal depended almost entirely on his mother for guidance, parental companionship, attention, and comfort. $\mathrm{Hal}$ and his mother would sit for hours, he telling her his problems and concerns and she telling him hers. He looked upon her as the only person to whom he could talk and she received some of the satisfaction from him that might have come from Mr. Barlow had he been less harsh and demanding. Now, when Hal's relationship with his father improved, his mother's source of comfort and satisfaction disappeared. This seemed to trigger the explosion in the marriage.

This shift in family balance necessitated a change in counseling focus. Now the worker saw Mr. and Mrs. Barlow individually and jointly in an effort to explore and to try to reestablish equilibrium in the marriage relationship. This was not easy, partly because they were in communication with their attorneys as well as with the worker over a period of months. The legal maneuvering served as a means of ventilating hostility and, in fact, they reached a separation agreement. One Saturday afternoon Mr. Barlow helped his wife to pack and drove her and their daughters to her parents' home in another state. Hal remained with his father.

On Monday morning, when the worker arrived at the office, Mr. Barlow was waiting with eyes reddened from a weekend of crying. This tightfisted, tough, domineering man said he could not bear to live without his wife. He feared that he could not keep his sanity living alone and even hinted suicide might be the best way out of his dilemma. He calmed gradually during the ninety-minute interview. The worker remarked that he was a man with strengths and weaknesses, just like all other men, and that to admit and recognize one's weaknesses is the mark of a real man, not the reverse. Then there was talk of alternatives for him and he decided that the best thing to do was to go to his wife and try to make peace with her in the light of what he now knew about himself. They were reconciled in a week and, using additional counseling help, established a much more appropriate, complementary relationship. In the fall, the old problems of Hal's poor school achievement and poor behavior reappeared. $\mathrm{He}$ was then seventeen and a half and was still nearly two years away from completing high school. At that point, however, the family was sound enough as a unit so that a mutually satisfying decision could be reached. Hal enlisted in the Navy and completed basic training near the top of his class of recruits. 


\section{Additional Tool}

Family-focused counseling is intended not to replace but to augment current practice. It is suggested as an improvement on, not an alternative to, what is now being done in probation and child welfare settings. "Those of us in the helping professions must learn to select those concepts which are of most use to us and to incorporate them, a few at a time, into our practice." $\theta$ Family-focused counseling may be viewed as a tool that may prove to be helpful to one, a few, or to many of the client families about which probation and child welfare workers are so vitally concerned.

8 Weiss and Monroe, supra note 2, p. 87. 